\title{
Trademarks must not go generic
}

\author{
Neil White and Simon Cohen
}

\section{The worldwide registration by a pharmaceutical company of the word taxol as a trademark suggests that procedures for registering such marks needs to be tightened.}

THE news that the pharmaceutical company Bristol-Myers Squibb has registered the name taxol as a trademark in nearly 70 countries worldwide, potentially giving them the right to prevent anyone else from using the name, has given rise to widespread comment in the scientific community ${ }^{1}$.

The company is seeking a monopoly on the name, even though it has been used by scientists throughout the world for many years to describe a chemical isolated from the pacific yew tree Taxus breviofolia. That product is still undergoing trials. But it appears to help in the treatment of cancer, and Bristol-Myers Squibb wishes to use the name to describe its own proprietary cancer treatments, benefiting from the reputation of a natural product.

The widespread comment that this has provoked suggests that many consider the company's move to be inappropriate ${ }^{2}$. But the real question is how the registration come to be allowed by the trademark registries of the world in the first place. If examiners had been aware of the background to the application and made the required searches, they would surely have looked at it in a different light.

Trademark examiners carry out certain rudimentary searches before allowing a mark to be registered. For example, they look through the existing trademarks listed on the register and in other publicly available compilations, such as dictionaries. Apparently this search turned up nothing to challenge the company's trademark application. But a glance at any compendium of chemical terms, such as the Merck Index, would have revealed that taxol is used by scientists to describe the product isolated from Taxus breviofolia.

The immediate implication is that registries should adapt their searches to suit the type of proposed trademark being considered. Research on a chemical or pharmaceutical trademarks such as taxol should be carried out differently than one on ordinary words such as Budget (services involving the renting of vehicles and considered unregistrable), Mothercare (signifying equally care by mothers and care for mothers and held registrable) and, of course, Nature.

Trademark protection has traditionally given less attention than patents in com-

This is one of an occasional series of articles on intellectual property and the law. merce. But a genuine trademark, if properly policed, can be an invaluable asset. For example, whereas patent protection lasts for a limited period of time - in Europe, this is 20 years from filing trademark protection can potentially last for ever, as long as renewal fees are paid and the mark does not become part of everyday vocabulary.

A trademark need not be a word but can be a distinctive shape or get-up (or even perhaps a smell or sound). Although under the previous law, the UK House of Lords refused to register the distinctive shape of the Coca-Cola bottle, in contrast they allowed the registration of SmithKline Beecham's multi-colour pharmaceutical capsules. Under the Trade Marks Act 1994, it is expected that distinctive shapes and get-ups will become easier to register.

The significance of brand names and trademarks is widely recognised by accountants, and the asset value of trademarks is reflected in the balance sheets of companies. Examples such as Coke, Xerox and Band-aid each demonstrate how a trademark can become an extremely valuable property.

A trademark indicates that goods or services come from a particular source, distinguishing them from the comparable goods or services of competitors. But a word in everyday use cannot be captured and monopolised by registering it for use in this way. In a recent case, for example, the British Trade Marks Registry ruled that the company Budget Rent-A-Car Corporation should not be allowed to register marks consisting of the word budget for services that involve renting vehicles.

The company argued that it had spent heavily on promoting the name Budget, and that the trademark had been used widely and intensively. But the registry decided that budget could not be treated as distinctive in law, as the word had acquired the meaning of "cheap" or "inexpensive", and other traders might legitimately wish to use it in promoting their own car hire services.

Nor does the registry allow words that refer directly to the character of goods. Thus applications to register Vapirub (for vapour rubs) and Crunch (for crunchy chocolate bars) have both been rejected. By contrast, words with only an indirect reference to the characteristics of goods, such as Aphrodisia (for soaps and per- fumes) have been allowed. So have ambiguous words lacking any direct reference to the goods covered, such as Mothercare, signifying equally 'care by mothers' and 'care for mothers'.

Even if initially distinctive, a valuable name can, if not properly handled, lose its trademark significance and become the generic name for the goods or services being provided. If this occurs, the name no longer functions as a trademark, as it does not distinguish the goods of a particular company. Many former trademarks, including escalator, yo yo, trampoline and gramophone, have suffered this fate, commonly referred to as 'genericide'.

Once a trademark has been obtained, great care must therefore be taken to ensure that it does not become used generically. The temptation to use a trademark to describe a particular type of goods is risky. If the trademark is used in speech or writing, it should legally be as an adjective ("I've got a Hoover vacuum cleaner"), not as a noun ("I've got a Hoover").

For the trademark owner, the key is choosing a trademark carefully. A name that is too descriptive or too similar to the product involved may make it difficult to argue that, as a trademark, the name distinguishes a particular product. At the same time, unless the trademark has some connection with the product, it may not catch on and establish the desired reputation. Examples of marks that refer to the product covered include Tagamet forSmithKline Beecham's anti-ulcer drug Cimetidine, Weetabix, Fybogel and Walkman.

As for taxol, even though the mark has now been successfully registered, this may not be the end of the matter. As other companies with an interest in cancer treatments will be aware, mechanisms exist for revoking trademarks if it is considered that they do not distinguish the products in question.

But more importantly, the success of Bristol-Myers Squibb in registering the mark suggests that there should be a tightening up of the registration procedure. Perhaps the current controversy will provide the impetus for such a move.

The authors are solicitors at Taylor Joynson Garrett, 50 Victoria Embankment, London EC4Y ODX, UK.

\footnotetext{
1. Nature 373,$370 ; 1995$

2. Nature 374,$208 ; 1995$
} 